\title{
Study of functional outcome of total hip arthroplasty in a series of cases of hip pathologies done in rural population
}

\author{
Rahul Kadam, Pankaj Bansal*, Abhay Chhallani
}

Department of Orthopaedics, M G M Medical College, Navi Mumbai, India

Received: 28 September 2016

Accepted: 17 October 2016

*Correspondence:

Dr. Pankaj Bansal,

E-mail: manishkkn1120@gmail.com

Copyright: ( $)$ the author(s), publisher and licensee Medip Academy. This is an open-access article distributed under the terms of the Creative Commons Attribution Non-Commercial License, which permits unrestricted non-commercial use, distribution, and reproduction in any medium, provided the original work is properly cited.

\section{ABSTRACT}

Background: The objective of the study was to assess the functional outcome of total hip arthroplasty (THA) done in a series of cases of hip pathologies rural population.

Methods: A retrospective randomized controlled study conducted in 50 cases of hip arthritis (38 males and 12 females) treated with uncemented THA for an average follow-up of 2 years at department of orthopedics MGM Medical College, Kamothe, Navi Mumbai. Harris hip scoring system was used for the functional scoring and the postoperative radiographs were assessed by Gruen zones for the femoral component and DeLee and Charnley zones for the acetabular component. All patients were evaluated pre operatively and post operatively 3 months 6 months, 12 months, 2years with Harris Hip score.

Results: $81 \%$ of our patients scored 85 points or better for a rating of excellent by Harris hip score system. $90 \%$ patients had little /no pain post operatively, whereas walking ability improved and was unlimited in $80 \%$ of the patients post operatively. Harris hip score improved from 40 to $80.80 .5 \%$-excellent, $13.80 \%$-good, $5.7 \%$-fair results. Poor results were not seen in any patient.

Conclusions: THR provided excellent pain relief, adequate stability, and remarkable range of motion in severely painful, refractory hip. A significant improvement was seen at two year follow-up.

Keywords: Total hip arthroplasty, Hip arthritis, Harris hip score, Hip pathologies

\section{INTRODUCTION}

Total hip arthroplasty (THA) is commonly performed in patients with hip pathologies. The goals of total hip arthroplasty are to relieve pain, to provide motion with stability and to correct deformity so that they could return to their normal daily activities. ${ }^{1}$ The greatest amount of functional improvement is observed within 6 months postoperatively, with further improvements occurring for up to 2 years. $^{2,3}$ Due to rapid advancements in surgical techniques and other developments by healthcare professionals the number of patients undergoing THA has increased to achieve excellent outcomes, with early functional recovery and short hospital stays. ${ }^{4}$
Since surgeons have tried to give better function to a painful, damaged joint through the stages of extraarticular pseudoarthrosis, simple resection arthroplasty, interpositional arthroplasty, hemiarthroplasty and to the present era of total joint replacement. ${ }^{1}$ THA originally was indicated for the alleviation of incapacitating pain in patients older than 65 years who could not be relieved sufficiently by nonsurgical means and for whom the only surgical alternative was resection of the hip joint (girdle stone resection arthroplasty)..$^{5}$

THR involves surgically removing the arthritic parts of the joint (cartilage and bone) replacing the "ball and socket" part of the joint with artificial components made from metal alloys and placing high-performance bearing 
surface between the metal parts. Most commonly the bearing surface is made from a very durable polyethylene plastic but other materials (including ceramics newer plastics or metals) have been used. A bewildering number of different implant designs bearing surface materials and surgical approaches have been tried to achieve one seemingly straightforward goal: to give a painless mobile hip improving the quality of life for patients who have hip arthritis. The aim of this study was to assess the clinical and functional improvement in THR patients in terms of early joint function and stability of the hip joint and also to assess complications of procedures.

\section{METHODS}

Our study was done in the department of Orthopedics, MGM Medical College, Navi Mumbai. A total of 50 patients who were admitted in our institute for the management of hip pathologies for a period of 2 years were considered for the study. Patients who had meet specific inclusion \& exclusion criteria were enrolled in our study. Institutional ethics committee permission was taken. A standard surgical technique using Southern approach was used by a single surgeon and Deputy or Zimmer prosthesis was used depending upon the patient's affordability and choice. ${ }^{6}$ Clinical and radiographic outcomes were assessed at a mean period of 2 years. Harris hip scoring system was used for the functional scoring and the postoperative radiographs were assessed by Gruen zones for the femoral component and DeLee and Charnley zones for the acetabular component. ${ }^{7-9}$ The formation of heterotopic ossification was graded according to the method described by Broker et al. ${ }^{10}$

\section{Postoperative considerations}

Day of operation, the patient is mobilised at approximately 4 hour post-operatively, under physiotherapist supervision. Straight leg raising exercises are encouraged, and a pillow is placed between the two limbs to prevent any position able to provoque dislocation. Intravenous patient- controlled-analgesia (PCA) systems or other analgesic schedule plan is started for overnight analgesia.

First postoperative day the postoperative haemoglobin level is measured. The patient controlled analgesia (PCA) was discontinued, but only after commencement of the pre-prescribed analgesic regimen, to ensure that pain levels are well controlled throughout the recovery period. Regular anti-emetics are continued, and the patients undergo further range of motion, and exercises twice a day under control of the physiotherapist. Walking with a frame is started.

On second, third, fourth postoperative day the drainage was removed. The patients continued to walk with the assistance of a frame or walking sticks. Active exercises are encouraged.
Fifth and subsequent postoperative days the patients are encouraged to walk safely without support. Functional exercises and advices are shown to prevent bad positioning of the limb Exercises of muscles reinforcement, and stability are performed.

\section{Statistical analysis}

Descriptive data are expressed as frequency and percentages, and means with SD. A value of $\mathrm{P}<0.05$ was considered statistically significant. Statistical analyses were performed using SPSS 20.0.

\section{RESULTS}

In our study, there was higher number of male $(\mathrm{n}=38)$ as compared to female $(n=12)$ with mean age of 38 years (male), 51 years (female). Amongst various hip arthritis there was osteoarthritis (12), avascular necrosis (35), rheumatoid arthritis (2), ankylosing spondylosis (6), psoriatic arthirits (1) as given in Figure 1.

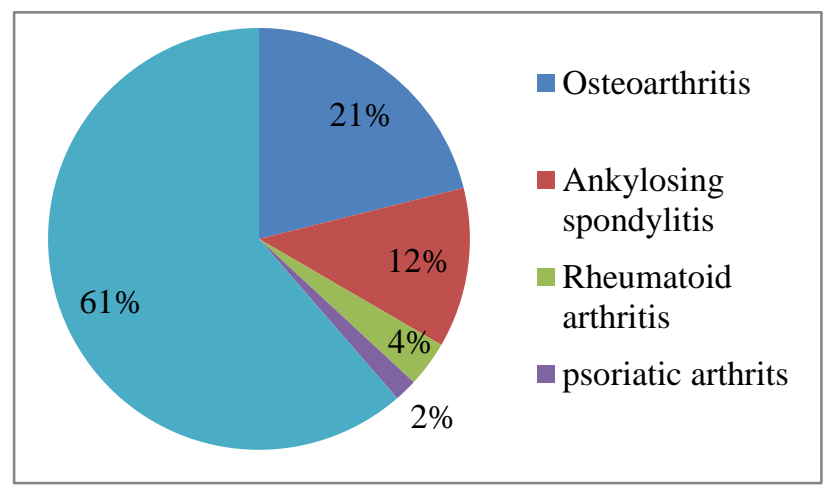

Figure 1: Types of hip arthritis.

Our study reveals, post operatively $80.81 \%$ patients had excellent, $14.85 \%$ patients had good and $5.4 \%$ patients had fair results clinically \& functionally. There were no poor results. Mean operative time performed for each case was $70 \mathrm{~min}$ (range 64-78 min). The average amount of bleeding was $150 \mathrm{ml}(122 \mathrm{ml}-180 \mathrm{ml})$ intraoperatively and about $50 \mathrm{ml}(40 \mathrm{ml}-88 \mathrm{ml})$ in postoperative drain. Hospitalization was 8 days in an average range. At follow up average HHS was 85 (range 74-96). Radiolucent lines were observed in one acetabular and two femoral components, but no secondary interventions were performed as patients were asymptomatic. Heterotropic ossification was observed in 3 patients with Brooker grade II. The mean HHS improved from 42.4 to 85 (p $<0.01$ ). The mean LLD decreased from 4.2 to $1.1 \mathrm{~cm}$, while the thigh circumference increased by a mean of 1.6 $\mathrm{cm}$

One patient developed UTI which was successfully managed by catheter removal and proper antibiotic coverage and increased hydration. One patient developed superficial wound infection which was managed successfully by conservative treatment. One patient 
developed traumatic dislocation which was managed by closed reduction and traction for 6 weeks. There were two patients in which intraoperative reduction could not achieve. Incision line closed with the joint dislocated. Both the patients were applied skeletal traction with increasing upto $15 \mathrm{kgs}$ for 6 weeks. After 6 weeks patient were taken into operation theatre and acetabular cup were revised. Joint reduction achieved intraoperatively. Bed mobilization started after 2 weeks postoperatively and weight bearing started after 3 weeks. Complications like deep vein thrombosis were absent due to thromboprophylaxis with injection Clexane $0.6 \mathrm{ml}$ for at least 3 days postoperatively Other complications like vascular injuries, skin necrosis, thromboembolism, fat embolism, joint instability, peri-prosthetic fractures were absent. Post-operatively, hips had a mean flexion arc of 114 degrees and 9 degrees of flexion contracture. The mean abduction and rotation were 25 and 50 degrees, respectively. The overall HHS with a mean of $85( \pm 15$, range $24-100$ ) was excellent in $80.5 \%$, good in $13.80 \%$, fair in $5.7 \%$ of cases as shown in Figure 2. Pain relief was achieved in 47 cases $(90.6 \%)$, improvement in walking in $42(92.8 \%)$, and improved ability in performing daily living activities in $39(88 \%)$.

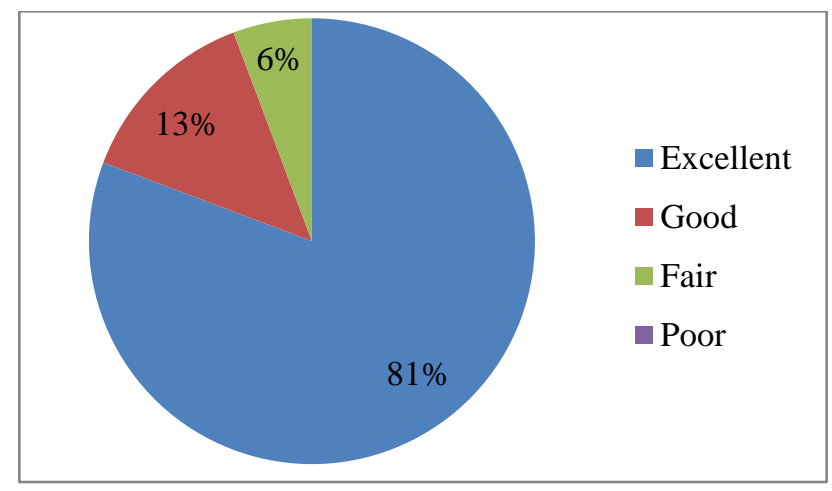

Figure 2: Harris hip score.

\section{DISCUSSION}

In our study we present a case series of 50 patients who underwent total hip arthoplasty with age group 19 to 65 , average being 38 years $(\mathrm{M}), 51$ years $(\mathrm{F})$ in which different sets of implants were used mostly uncemented metal on polyethylene.

Improved poly-ethylene sterilization and storage and more recently cross linking have significantly reduced the wear and associated osteolysis and component loosening and failure. $^{11,12}$

Heterotropic ossification was present in 3 patients at follow up. The low incidence in the present study could be due to minimum soft tissue dissection and nonsteroidal anti-inflammatory drugs post operatively for 710 days and meticulous removal of cement particles and products of reaming from the soft tissue around the hip. $^{13,14}$ Use of antibiotic prophylaxis (cefaparazone +salbactum and teicoplanin) was based on the studies in favour of the use of systemic antibiotic in orthopaedic surgery by Bryan et al. ${ }^{15,16}$ Wilson et al reported significant decrease in the infection rate when prophylactic antibiotic was used, from $11 \%$ to $1 \% .^{15,16}$ Cementless implant is dependent on bone ingrowth and biological stabilization process which is slow in elderly patients as they have limited reserves. Young patients often have a small diaphyseal diameter which would require use of a smaller sized stem, if cementing, to accommodate adequate cement mantle. However, this is not the problem with the normal and wide femoral canal of the adult and elderly patients. ${ }^{17}$ Fat embolism has also been reported in literature in procedures in which cement was not used. In our study there was no case reported with fat embolism. ${ }^{18-20}$ Young et al (1998) studied regarding patient factors pertinent to the outcome of total hip arthroplasty. They concluded that best functional outcome and prosthesis survival rate were among patients who were between 45 and 75 years of age, weight less than $70 \mathrm{~kg}$, had strong social support, had a higher educational level, had better preoperative functional status and had no co morbid disease. ${ }^{21,22}$

In spite of these numerous modifications, aseptic loosening of components emerged as the single most still unsolved long term complication of cemented or cementless Total hip arthroplasty. ${ }^{13}$ Preoperative planning to match patients and implants, restoration of hip center and biomechanics are important components. Similarly intraoperative attention to offset, leg length, component orientation, stability and motion without impingement are critical. The surgical expertise and experience affect the outcome of total hip arthroplasty. THA is a single dependable procedure in elderly patients whose general health and medical comorbidities preclude repeated operations. ${ }^{22}$

\section{CONCLUSION}

Total hip arthroplasty have in the past four decades revolutionized the treatment of arthritic hip. With these excellent results we conclude that total hip arthroplasty provided total relief, adequate stability, remarkable range of motion in severely painful, refractory hips, if performed taking into consideration pre-operation selection of patients, intra operative soft tissue balancing, correct overall alignment of prosthesis and postoperative proper rehabilitation of patients. Total hip arthroplasty is a relatively safe and sure procedure in the hands of the experienced or the guided. It forms the integral part of the general orthopedic set up and with proper patient selection; proper procedure and rehabilitation could continue to achieve the same promises as we have seen it to show. In the Indian subcontinent (developing countries), patients are poor and economic constraints are there. So, uncemented THA is cost effective single stage procedure with good and acceptable results in long term follow-up. With continued technical advances, the longetivity of the implants will improve. 


\section{ACKNOWLEDGMENTS}

We thank our HOD, Guide, my colleagues, my parents and the patients for their collaboration.

Funding: No funding sources

Conflict of interest: None declared

Ethical approval: The study was approved by the institutional ethics committee

\section{REFERENCES}

1. Turek SL. The Hip. In: Orthopaedic Principle and their Application. Volume 2. $4^{\text {th }}$ edn. Philadelphia: Lippincott - Raven Publishers; 2002: 1124-33, 1194-1200.

2. Long WT, Dorr LD, Healy B, Perry J. Functional recov ery of noncemented total hip arthroplasty. Clin Orthop Rel Res.,1993;288:73-7.

3. Kennedy DM, Hanna SE, Stratford PW, Wessel J, Gollish JD. Preoperative function and gender predict pattern of functional recovery after hip and knee arthroplasty. J Arthroplasty. 2006;21(4):55966.

4. Ibrahim MS, Khan MA, Nizam I, Haddad FS, Perioperative interventions producing better functional outcomes and enhanced recovery following total hip and knee arthroplasty: an evidence-based review. BMC Medicine. 2013;11(1):37.

5. Berend ME, Thong AE, Faris GW, Newbern G, Pierson JL, Ritter MA. Total joint arthroplasty in the extremely elderly: hip and knee arthroplasty after entering the 89th year of life. J Arthroplasty. 2003;18(7):817-21.

6. Osboren RP. The approach to the hip joint. Critical review. JBJS. 1930;18:49.

7. Harris WH. Extensive exposure of the hip joint. Clin Orthop Relat Res. 1973;91:58-62.

8. Gruen TA, McNeice GM, Amstutz HC. Modes of failure of cemented stem type femoral components: a radiographic analysis of loosening. Clin orthop Relat Res. 1979;141:17-27.

9. DeLee JG, Charnley J. Radiological demarcation of cemented sockets in total hip replacement. Clin Orthop Relat Res. 1976;121:20-32.

10. Brooker AF, Bowerman JW, Robinson RA, Riley LH Jr. Ectopic ossification following total hip replacement. Incidence and a method of classification. J Bone Joint Surg Am. 1973;55(8):1629-32.

11. GX Ni, WW Lu, KY Chiu. Cemented or uncemented femoral component in primary total hip replacement? A review from a clinical and radiological perspective. J Ortho Surg. 2005;13(1):96-105.
12. Saikko V, Calonius O, Keranen J. Wear of conventional and cross-linked ultra-high-molecularweightpolyethylene acetabular cups against polished and roughened $\mathrm{Co} \mathrm{Cr}$ femoral heads in a biaxial hip stimulator. J Biomed Mater Res. 2002;63(6):848-53.

13. Buckwalter AE, Calaghan JJ, Liu SS, Pedersen DR, Goetz DD, Sullivan PM, et al. Results of Charnley total hip arthroplasty with use of improved femoral cementing technique. A concise follow-up, at a minimum of twenty-five years, of a previous report. J Bone Joint Surg Am. 2006;88(7):1481-5.

14. Thmpson R, Kane RL, Gromala T, McLaughlin B, Flood S, Morris N, et al. Complications and short term outcomes associated with total hip arthroplasty in teaching and community hospitals. J Arthroplasty. 2002;17(1):32-40.

15. Wilson PD Jr, Aglietti P, Salvati EA. Subacute sepsis of the hip treated by antibiotics and cemented prosthesis. J Bone Joint Surg Am. 1974;56(5):87998.

16. Bryan CS, Morgan SL, Caton RJ, Lunceford EM Jr. Cefazolin versus cefamendole for prophylaxis during total joint arthroplasty. Clin Orthop Relat Res. 1988;288:117-22.

17. Canale ST. Arthroplasty of Hip. In: Campbell's Operative Orthopaedics. Volume 1. $10^{\text {th }}$ edn. Philadelphia: Mosby Publishers; 2008: 346-351.

18. Christie J, Burnett R, Potts HR, Pell AC. Echocardiography of transarterial embolism during cemented and uncemented hemiarthroplasty of the hip. J Bone Joint Surg Br. 1994;76(3):409-12.

19. Pitto RP, Koessler M, Draenert K. The John Charnley Award. Prophylaxis of fat and bone marrow embolism in embolism in cemented total hip arthroplasty. Clin Orthop Relat Res. 1998;355:23-34.

20. Ries MD, Lynch F, Rauscher LA, Richman J, Mick C, Gomez M. Pulmonary function during and after total hip replacement. Findings in patients who have insertion of a femoral component with and without cement. J Bone Joint Surg Am. 1993;75(4):581-7.

21. Young NL, Chaeh D, Waddell JP, Wright JG. Patient characteristics that affect the outcome of total hip arthroplasty: a review. Can J Surg. 1998;41(3):184-5.

22. Katz JN, Losina E, Barret J, Phillips CB, Mahomed $\mathrm{NN}$, Lew RA, et al. Association between hospital and surgeon procedure volume and outcomes of total hip replacement in the United States medicare population. J Bone Joint Surg Am. 2001;83(11):1622-9.

Cite this article as: Kadam $\mathrm{R}$, Bansal $\mathrm{P}$, Chhallani A. Study of functional outcome of total hip arthroplasty in a series of cases of hip pathologies done in rural population. Int J Res Orthop 2016;2:269-72. 